\title{
Reflective practice in psychiatric training: Balint groups
}

\author{
Sami Omer, Geraldine McCarthy
}

Ir J Psych Med 2010; 27(3): 115-116

Reflective practice is becoming increasingly recognised as an important tool for professional development of doctors. It is considered as the 'ability of doctors to think critically about their own reasoning and decisions.' An example of reflective practice in psychiatric training is the use of the case-based discussions. In the UK, The Royal College of Psychiatrists requires trainees to attend case-bases discussions as part of their psychotherapy training. ${ }^{2}$ In Ireland, attending $\mathbf{3 0}$ sessions of Balint groups (a form of case-based discussions) is a mandatory requirement for basic specialist training in psychiatry. $^{3}$

Balint groups are named after Michael Balint, a Hungarian psychoanalyst who worked in the UK in the 1950s. Balint joined the Tavistock clinic in London in 1948. ${ }^{4}$ In 1950 , together with his future wife Enid, they held seminars for general practitioners. The focus of those seminars was to examine the doctor-patient relationship: what it meant, how it could be used helpfully, why it so often broke down with doctor and patient failing to understand each other.

Balint described his techniques in his seminal book The Doctor, His Patient and the IIIness. ${ }^{5}$ In the book he explored several aspects of the doctor-patient relationship such as the 'doctor as a drug' and 'collusion of anonymity'. Balint continued to work with groups as well as travelling to disseminate his ideas until his death in $1970 .{ }^{4}$ Over the years Balint groups have evolved to become a worldwide movement spearheaded by the International Balint Federation with 21 member countries mostly in the western hemisphere. ${ }^{6}$

Here, we outline the structure and process of Balint groups and describe our experience in Sligo mental health services.

\section{What is Balint training for?}

Samuel ${ }^{7}$ identifies the aims and objectives of Balint training are as follows:

- To encourage doctors to value their interpersonal skills and learn to understand their limits

- To improve the doctor's perception and understanding of their patients communication

- To allow doctors to become aware of their blind spots in their interaction with patients.

*Sami Omer, MSc, MRCPsych, Senior Registrar, Sligo/Leitrim Mental Health Services. Email: omersami@hotmail.com Geraldine McCarthy, MD MRCPsych DCH CAT practitioner, Consultant in Psychiatry of Old Age, Honorary Senior Lecturer NUIG, Sligo/Leitrim Mental Health Services, Education Centre, Ballytivnan, Sligo, Ireland.

*Correspondence

SUBMITTED: MARCH 23, 2010. ACCEPTED APRIL 27, 2010.

\section{Table 1: Essential characterislies of a Balint group}

(adapted with permission from the British Balint Society)

- Small group of 6-12 participants

- Defined group leader

- Group members are in clinical contact with patients

- The material of the group is based on the presentation of current cases giving the presenting clinician cause for thought

- The discussion focuses on the relationship between the presenting doctor and his patient

- Casenotes should not be used

- The group should not be used for personal therapy

- Standard rules for small group working apply

- The purpose of the group is to improve understanding of the patient's problems, not to find solutions

\section{Group structure}

Balint groups are usually small with the number of participants ranging from six to 12 . The group meets weekly or fortnightly, and each week a participant brings up a case for discussion by the group. The essential characteristics of a Balint group are summarised in Table 1.

Effective leadership is the key to success of a Balint group. Traditionally, Balint groups were led by psychoanalysts but it is now accepted that other professionals such as GPs and psychiatrists could be Balint leaders. The International Balint Federation developed a set of guidelines for the accreditation of Balint group leaders. ${ }^{8}$ Based on their own research of 21 experienced Balint group leaders; Johnson et $a^{\beta}$ list the essential characteristics of effective Balint group leader as follows:

- Creates climate of safety, acceptance, and trust

- Establishes and maintains group norms

- Promotes movement toward the group's task

- Understands group process

- Personality/style of the leader.

\section{Effectiveness of Balint groups}

The body of research on Balint groups comes from family medicine/general practice. Studies on effectiveness of Balint training are fraught with methodological difficulties such as small sample sizes and lack of control groups.

In the US, family practice residents who frequently attended Balint groups reported that it helped their interaction and understandings of difficult patients as well as helping them develop empathetic skills. However, the discomfort of 
presenting cases deterred some residents from attending Balint groups on a regular basis. ${ }^{10} \mathrm{~A}$ controlled study of family medicine residents/showed that Balint training led to self-reported improvement in psychological medicine skills. ${ }^{11}$ A study of GPs who, took part in a Balint group in Sweden found that the participants reported more positive feelings about their work and their relations to the patients than the control group. ${ }^{12}$

There is limited literature on the effectiveness of Balint groups in psychiatric training. A narrative report by trainees who attended a Balint group in the UK indicated that initially trainees found the experience anxiety provoking, but they stated that they enjoyed the experience as the group progressed and found it helpful to change attitudes towards difficult patients. ${ }^{13}$

In a more recent study of a group of psychiatric residents and counsellors who participated in a Balint-style case discussion groups in the UK, most of the participants reported learning new skills such as developing "an awareness of their own feelings towards patients and increased their ability to stay with, rather than withdraw, from difficult feelings." ${ }^{13}$ Nonetheless, the groups were anxiety provoking and some participants struggled to adapt. To overcome this, the authors suggest active involvement from group leaders to alleviate anxiety by avoiding jargon, not allowing prolonged silences, and not interpreting group dynamic. ${ }^{14}$

\section{Sligo experience}

In September 2009, we started a Balint group for psychiatric trainees (6-8) in Sligo. The group leader ( $\mathrm{GMcC}$ ) has previous experience in Balint groups and is trained in cognitive analytic therapy. The group was co-led by a senior registrar (SO). It was open to all psychiatric and GP trainees. We met every Wednesday morning for one hour and each week one of the trainees presented a case for discussion by the group.

The leaders of the group encouraged trainees to focus on the doctor-patient interaction and reflect on their emotional reactions rather than the actual management of cases. The group was held in a 'trusting' non judgemental environment.

Our experience was not dissimilar to that described by Das et $a /^{13}$ in that initially trainees were reluctant to present cases but as the group progressed the level of participation in the group improved. Informal feedback from the psychiatric trainees indicated that they enjoyed having the opportunity to reflect on 'difficult' cases. Another positive feedback was the ability to share information with other trainees and the feeling of solidarity it creates; one of the trainees described it as feeling 'everybody is in the same boat'.

Feedback has been also very positive from the GP trainees themselves as well as their trainers. They found it very useful to address the doctor-patient relationship from a different perspective. They (GP trainees) were very active participants from the start of the group and have continued to be involved. They also liked the fact that this group format had been developed in primary care.

The main criticism of the group was that cases tended to be repetitive. This was found to be both a positive and negative issue. For some trainees, particularly newer trainees and the GP trainees, the fact that others had similar problems with the same difficult patients on call was helpful. It meant that addressing the doctor-patient relationship with one difficult case could help with other similar difficulties.

On the negative side, some cases were presented a number of times by different trainees. However even on these occasions, the feedback was felt to be useful and transference could be addressed.

Repetitiveness of cases is probably a reflection of the newness of the group. Trainees were inclined to follow in the footsteps of their colleagues when presenting cases. This is also a reflection on our leadership style of the group as we deliberately adopted a non-prescriptive approach. The size of our group was probably too small. This became evident when some of the trainees were on leave and/or when the time of the group clashed with on-call and other clinical commitments.

\section{Conclusions}

Overall, the development of a Balint group has been a positive experience for both the trainees and the co-chairs. The attendance has increased over time and all trainees have been keen to discuss cases. The group was also open to the GP trainees who participate in the training scheme and rotate on a four monthly basis. Their feedback has been very positive, both directly to the group and via their scheme organiser. It has also facilitated further interest in the various modalities of psychotherapy available, as well as increased understanding of transference and counter-transference in the clinical setting.

Although psychotherapy is an essential and mandatory part of psychiatry training, some trainees find it difficult to 'get started', the Balint group serves as an introduction that is both useful and enjoyable.

Declaration of Interest: None.

\footnotetext{
References

1. Mamede S, Schmidt HG. The structure of reflective practice in medicine. Med Educ 2004; 38(12): 1302-8

2. Royal College of Psychiatrists. Training in Psychotherapy for ST1-3. www.repsych. ac.uk/pdf/Training\%20in\%20psychotherapy\%20for\%20St\%201.pdt

3. The College of Psychiatry of Ireland. Basic Training Handbook. Accessed January 2010. www.irishpsychiatry.ie/psychiatric_training_committee.aspx

4. Lakasing E. Michael Balint - an outstanding medical life. Br J Gen Pract 2005; 55(518): 724-725

5. Balint M. The Doctor, His patient and the illness. 2nd Ed. Churchill Livingstone: Edinburgh, 1957 (reprinted 2005).

6. The International Balint Federation. Accessed January 2010. www.balintinternational. com/membercountries.html

7. Samuel OW. Aims and objectives of Balint training. J Balint Soc 1987; 15: 23-5.

8. Salinsky J. The Balint movement worldwide: present state and future outlook: a brief history of Balint around the world. Am J Psychoanal 2002; 62(4): 327-35.

9. Johnson AH, Nease DE Jr, Milberg LC, Addison RB. Essential characteristics of effective Balint group leadership. Fam Med 2004; 36(4): 253-9.

10. Musham C, Brock CD. Family practice residents' perspectives on Balint group training: in-depth interviews of frequent and infrequent attenders. Fam Med 1994; 26(6): 382-6.

11. Turner AL, Malm RL. A preliminary investigation of Balint and non-Balint behavioural 11. Turner AL, Malm RL. A preliminary investigation of
medicine training. Fam Med $2004 ; 36(2): 114-122$.

12. Kjeldmand D, Holmstrom I, Rosenqvist U. Balint training makes GPs thrive better in their job. Patient Educ Couns 2004; 55(2): 230-5.

13. Das A, Egleston $P$, Elsayeh $\mathrm{H}$ et al. Trainees' experience of a Balint group. Psychiatric Bull 2003; 27: 274-275.

14. Graham S, Gask L, Swift G, Evans M. Balint-style case discussion groups in psychiatric training: an evaluation. Acad Psychiatry 2009; 33(3); 198-203.
} 